Jurnal Psikologi Teori dan Terapan

2016, Vol.7, No. 1, 16-25, ISSN: 2087-1708

\title{
Pengaruh Mind Control Training Terhadap Peningkatan Konsentrasi Pada Atlet Putri UKM Bola Voli Unesa
}

\author{
Nofy Ongko ${ }^{1}$, dan Miftakhul Jannah \\ Program Studi Psikolog Universitas Negeri Surabaya
}

\begin{abstract}
The study was aimed to determine the effect of Mind Control Training on concentration among female athletes of a volleyball student club in Universitas Negeri Surabaya (Unesa). This study used a quasi-experimental method with untreated control group design with dependent pretest and posttest samples. The subjects were sixteen female athletes who were divided into experimental and control groups. Mind Control Training treatment was given only in the experimental group, while the control group was not given any treatment. Data were obtained by performing the pretest and posttest in both groups with using Grid Concentration Exercise. Data were analyzed using wilcoxon test and gain score. The result shows that there is a significant difference between the concentration score before and after treatment in the experimental group (Sig. $=0,012, p<0,05$ ). In addition, the increase in the concentration of female athletes of student activity units volleyball Unesa can be seen from gain score in both groups, the experimental groups had an higher value of gain sccore than control group $(19,875>10)$. This means that the hypothesis of this study is accepted that the Mind Control Training is effective to increase the concentration of female athletes of volleyball student club in Universitas Negeri Surabaya.
\end{abstract}

Keywords: Mind control training, concentration, volleyball female athletes.

\begin{abstract}
Abstrak: Penelitian ini bertujuan untuk menguji apakah ada pengaruh mind control training terhadap peningkatan konsentrasi pada atlet putri unit Kegiatan Mahasiswa (UKM) Bola Voli Universitas Negeri Surabaya (Unesa). Metode penelitian yang digunakan adalah quasi experimental dengan untreated control group design with dependent pretest and posttest samples. Subjek penelitian ini berjumlah enam belas atlet putri yang dibagi menjadi kelompok eksperimen dan kelompok kontrol. Perlakuan berupa Mind Control Training hanya diberikan kepada kelompok eksperimen, sedangkan kelompok kontrol tidak diberikan perlakuan apapun. Data diperoleh melalui pretest dan posttest pada kedua kelompok menggunakan Grid Concentration Exercise. Analisis data menggunakan uji wilcoxon dan gain score. Hasil analisis uji wilcoxon menunjukkan terdapat perbedaan skor konsentrasi antara sesudah dan sebelum perlakuan Mind Control Training pada kelompok eksperimen $($ Sig. $=0,012, \mathrm{p}<0,05)$. Selain itu, peningkatan konsentrasi pada atlet putri UKM Bola Voli Unesa dapat dilihat dari nilai gain score pada kedua kelompok, nilai gain score pada kelompok eksperimen lebih tinggi dibandingkan dengan nilai gain score pada kelompok kontrol $(19,875>10)$. Hasil tersebut menunjukkan bahwa hipotesis penelitian ini dapat diterima, yaitu Mind Control Training berpengaruh terhadap peningkatan konsentrasi pada atlet putri UKM Bola Voli Universitas Negeri Surabaya.
\end{abstract}

Kata Kunci: Mind control training, konsentrasi, atlet putri bola voli.

Korespondensi tentang artikel ini dapat dialamatkan kepada Nofy Ongko melalui e-mail: azurefyno@ymail.com 
Olahraga merupakan suatu bentuk permaianan yang terorganisir dan bersifat kompetitif (Husdarta, 2011). Olahraga tidak hanya mencakup aspek fisik saja tetapi juga mencakup aspek psikologis seseorang. Hal tersebut tertuang dalam deklarasi International Council of Sport and Physical Education, yang menyatakan bahwa olahraga adalah setiap kegiatan fisik yang bersifat permainan dan yang berupa perjuangan terhadap diri sendiri atau orang lain atau terhadap kekuatan-kekuatan alam tertentu (Moeloek, 1984).

Pada dasarnya, olahraga memiliki banyak jenisnya ada bola basket, bola voli, sepak bola, renang, bela diri, dan lain sebagainya (Tim Musyawarah Guru Mata Pelajaran Pendidikan Jasmani Olahraga dan Kesehatan Kota Kediri, 2012). Olahraga bola voli merupakan salah satu jenis olahraga yang digemari oleh para mahasiswa dalam lingkup Unit Kegiatan Mahasiswa (UKM) Unesa. Bola voli merupakan suatu permainan yang dimainkan oleh dua regu dan masingmasing regu terdiri atas enam orang pemain (Tim Musyawarah Guru Mata Pelajaran Pendidikan Jasmani Olahraga dan Kesehatan Kota Kediri, 2012). Setiap regu berusaha agar dapat memukul dan menjatuhkan bola ke dalam lapangan melewati bagian atau jaring atau net dan mencegah pihak lawan dapat memukul dan menjatuhkan bola ke dalam lapangannya (Tim Musyawarah Guru Mata Pelajaran Pendidikan Jasmani Olahraga dan Kesehatan Kota Kediri, 2012).

Olahraga bola voli ini menuntut setiap atlet menguasai servis, passing, mengumpan (set-up), smash, dan membendung bola (blocking). Tentunya untuk melakukan serangkaian teknikteknik andalan tersebut, para atlet bola voli memerlukan tingkat konsentrasi yang tinggi. Kemampuan konsentrasi memegang kontribusi yang besar bagi atlet untuk mengerahkan seluruh kemampuan dan keterampilannya untuk memenangkan suatu pertandingan yang diikutinya.

Nideffer dan Sagal menjelaskan bahwa konsentrasi merupakan perubahan yang konstan yang berhubungan dengan dua dimensi yaitu dimensi luas atau width (broad atau narrow) dan dimensi pemusatan atau focus (internal atau external). Lebih lanjut lagi, Nideffer dan Sagal (2006) membagi konsentrasi menjadi empat jenis yaitu broad-external, broadinternal, narrow-internal, dan narrowexternal. Olahraga bola voli merupakan jenis olahraga yang membutuhkan pergerakan yang cepat sehingga membutuhkan dua jenis konsentrasi yaitu broad-external ketika mengamati lingkungan sekitar seperti melihat celah serta pertahanan dan posisi lawan lalu narrow-external ketika melakukan smash, servis, blocking, set-up, dan passing (Nideffer, 2000; Zep lin, dkk, 2014).

Proses shifting atau perpindahan konsentrasi dari broad-external ke narrowexternal yang dilakukan oleh atlet bola voli tidaklah mudah. Hal tersebut terlihat dalam observasi tanggal 15 September 2015 dimana atlet UKM Bola Voli Unesa mengalami kejadian seperti 1) ketika tosser memberikan kode "bola open" pada spiker, namun tidak menghiraukan; 2) cover tidak langsung mengambil posisinya di belakang block, padahal waktu itu cover seharusnya ada di belakang block; 3) servis pada saat mengumpan terkadang tidak tepat; 4) miss komunikasi saat mengumpan bola antar anggota, jadi semisal A mengumpan ke B dengan memberikan kode tapi B tidak langsung bergerak menerima bola yang diumpankan kepadanya; dan 5) tidak tepat saat memukul atau menerima bola.

Berdasarkan hasil wawancara pada enam atlet yang usai berlatih, mereka menyatakan apa yang terjadi disebabkan oleh 1) turunnya stamina atlet putri yang menyebabkan kelelahan tak dapat terelakkan; 2) pikiran kacau yang ada 
dalam diri atlet; 3) tangan mengepal dengan sendirinya sehingga gerakan menjadi berantakan; 4) sorakan dari penonton; 5) anggapan lawan sangat kuat dan tangguh; 6) poin-poin kritis lawan lebih unggul.

Fenomena diatas dapat dijelaskan dengan mengacu pada teori Nideffer dan Sagal (2006), sehingga dapat diperoleh penjelasan mengenai shifting atau perpindahan konsentrasi pada atlet putri UKM Bola Voli Unesa. Fenomena pertama ketika "tosser memberikan kode 'bola open' pada spiker dan tidak dihiraukan", pada saat itu spiker sedang mengamati lingkungan sekitar (broad-external) namun, spiker mengalami kegagalan konsentrasi yaitu saat tosser memberikan kode "bola open" (harusnya berpindah ke narrow-external tetapi masih di broadexternal). Konsentrasi atlet yang masih berada di broad-external padahal seharusnya sudah berpindah ke narrowexternal ini juga terjadi di fenomena selanjutnya.

Wilson, dkk (2006) dan Komarudin (2013) menjelaskan bahwa kegagalan shifting atau perpindahan konsentrasi atlet ini disebabkan oleh dua stimuli yaitu stimuli eksternal (sorakan penonton, poinpoin kritis) dan stimulis internal (turunnya stamina, pikiran kacau, mengepalnya tangan dengan sendirinya, dan anggapan lawan lebih kuat). Kesimpulan yang diperoleh berdasarkan fenomena yang terjadi adalah penurunan konsentrasi dimana atlet tidak bisa konsentrasi pada satu informasi relevan pada saat shifting atau perpindahan konsentrasi (Cox, 2002).

Penurunan konsentrasi merupakan masalah serius dalam pertandingan. Pencapaian prestasi yang gemilang, tidak hanya dipengaruhi faktor fisik dan teknik saja, melainkan faktor psikologis seperti konsentrasi juga mengambil peran penting (Adisasmito, 2007). Menurut Nideffer (2002) cara yang digunakan untuk mengatasi gangguan psikologis seperti penurunan konsentrasi menggunakan mental training. Penggunaan mental training yang baik, akan memberikan dampak positif bagi atlet yang berlatih dan bertanding (Wilson, dkk, 2006).

Wilson, dkk (2006) menjelaskan bahwa mental training yang digunakan untuk meningkatkan konsentrasi jenis Narrow yaitu menggunakan cue word atau picture. Cue word merupakan bentuk statement yang ditujukan ke atlet sendiri yang membantu untuk terfokus kembali (Hedstrom, 2015). Picture dalam hal ini bukan berarti gambar yang ada dalam kertas melainkan suatu visualisasi yang diciptakan oleh atlet (Zep lin, dkk, 2014). Visualisasi ini penting karena mereka menyediakan informasi eksternal yang dibutuhkan atlet ketika perpindahan konsentrasi (Nideffer, 2000). Visualisasi ini meliputi gambaran masa lalu atlet mengenai kejadian-kejadian yang serupa di masa sekarang (Gelinas dan Chandler, 2006).

Nideffer (2000) menambahkan kinesthetic feedback agar atlet lebih mudah dalam melakukan perpindahan konsentrasi. Kinesthetic feedback ini diperlukan agar atlet mengenali bentuk perasaan. Semakin positif perasaan atlet, maka akan semakin cepat atlet untuk berpindah konsentrasi dan tidak membutuhkan banyak waktu untuk menganalisis karena perasaan atlet sudah yakin (Nideffer dan Sagal, 2006).

Salah satu bentuk mental training yang menggabungkan antara cue word, visualisasi, dan kinsethetic feedback adalah Mind Control Training. Mind merupakan kunci utama dalam sebuah pertandingan. Atlet dengan mind yang baik atau tenang, maka tubuh akan mampu menampilkan kemampuan terbaik (Nideffer, 2000). Mind Control Training yang digunakan dalam penelitian ini mengacu pada Silva Method dimana dalam Silva Method ini menekankan pada proses meditasi, visualisasi, hipnosis, positive thinking, dan 
intuisi atau Extra Sensory Preception (Silva, 2007; Dyar, 2012).

Langkah-langkah Mind Control Training ini dibagi menjadi tiga tahap (Silva, 2007). Tahap pertama adalah meditasi, visualisasi, dan cue word. Tahap pertama ini diperlukan sebagai relaksasi agar atlet merasa tenang dan nyaman sebelum memasuki gelombang alpha di tahap kedua. Subjek yang memasuki tahap kedua ini memperoleh hipnosis, visualisasi, dan positive thinking. Pada tahap inilah subjek memasuki gelombang alpha untuk melakukan pemprograman ulang tentang konsentrasi (Navis, 2013).

Indikator bahwa seseorang memasuki gelombang alpha adalah matanya tertutup (Zhuang, dkk, 2009; Bazanova, 2012; Hurless, dkk, 2013), tidak tertidur dan tetap terjaga (Hurless, dkk, 2013), dalam keadaan rileks yang meliputi nafas dan denyut nadinya teratur serta telapak kaki terbuka ketika duduk selonjor (Zhuang, dkk, 2009; Hurless, dkk, 2013), mudah mendengarkan suara (Amini, dkk, 2014), dan gerak tubuh minim (Hurless, dkk, 2013; Amini, dkk, 2014). Ketika atlet memasuki gelombang alpha, disinilah positive thinking, visualisasi diberikan beserta kinesthetic feedback. Positive thinking dalam hal ini berfungsi untuk mengubah pikiran-pikiran negatif atlet selama bertanding. Extra Sensory Preception digunakan untuk mengoptimalkan kerja otak kanan melalu visualisasi dan kinesthetic feedback. Karena ciri khas dari Silva Method ini adalah menggunakan otak kanan (Silva, 2007).

Optimalisasi kerja otak kanan ini akan membuat atlet lebih mudah dalam membentuk pikirian kreatif saat melakukan visualisasi dan kinesthetic feedback ketika berada dalam gelombang alpha. Nugroho (2009) menyatakan bahwa dalam kondisi alpha, konsentrasi akan terpusat pada satu hal dalam satu saat, sehingga atlet dapat berkonsentrasi pada dirinya sendiri.
Pemusatan konsentrasi ini berguna untuk menyeleksi perhatian pada saat menjelang pertandingan sehingga atlet dapat berkonsentrasi saat bertanding (Langenati dan Jannah, 2015).

Tahap ketiga yang merupakan tahap terakhir merupakan tahap dimana atlet mulai tersadar kembali dari gelombang alpha dan mulai terfokus kembali. Silva (2007) menjelaskan bahwa dengan memanfaatkan teknik Mind Control dengan benar, maka konsentrasi akan terpelihara lebih baik. Berdasarkan uraian pentingnya manfaat dari Mind Control inilah, peneliti mengangkat Mind Control sebagai bentuk training yang diharapkan mampu meningkatkan konsentrasi atlet putri UKM Bola Voli Universitas Negeri Surabaya (Unesa).

\section{Metode}

Penelitian ini menggunakan metode quasi experiment dengan untreated control group design with dependent pretest and posttest samples. Desain ini digunakan untuk mengontrol variabel-variabel luar yang mempengaruhi pelaksanaan eksperimen. Pengaruh Mind Control Training terhadap peningkatan konsentrasi pada atlet putri UKM Bola Voli Unesa dapat dilihat dengan membandingkan tingkat konsentrasi atlet sesudah dan sebelum diberikan perlakuan. Berikut desain penelitian yang digunakan dalam penelitian ini:

Tabel. 1 Desain Eksperimen

\begin{tabular}{cccc}
\hline NRE & O1 & X & O2 \\
NRK & O1 & $(-)$ & O2 \\
\hline
\end{tabular}

$\begin{array}{ll}\text { Keterangan: } \\ \text { NRE } & =\text { Kelompok Eksperimen } \\ \mathrm{NRK} & =\text { Kelompok Kontrol } \\ \mathrm{O} 1 & =\text { Pretest } \\ \mathrm{O} 2 & =\text { Posttest } \\ \mathrm{X} & =\text { Perlakuan (Mind Control Training) } \\ (-) & =\text { Tidak diberi pelakuan }\end{array}$

Populasi dalam penelitian ini adalah atlet putri UKM Bola Voli Unesa yang berjumlah 50 atlet putri. Teknik sampling 
yang digunakan dalam penelitian ini adalah purposive sampling dengan kriteria sebagai berikut: Terdaftar secara aktif sebagai anggota unit mahasiswa bola volley Unesa; berjenis kelamin perempuan; tergolong dalam tingkat konsentrasi sangat kurang hingga cukup; bersedia mengisi informed consent dan menjalani perlakuan dalam penelitian. Berdasarkan kriteria tersebut, 16 atlet putri UKM Bola Voli Unesa berhasil dipilih menjadi sampel. 16 atlet putri UKM Bola Voli Unesa ini kemudian dibagi menjadi dua kelompok, yaitu kelompok eksperimen dan kelompok kontrol.

Teknik pengumpulan data dalam penelitian ini menggunakan observasi. Observasi dalam penelitian ini digunakan untuk mengamati jalannya proses pemberian perlakuan dan proses subjek penelitian memasuki gelombang alpha di tahap pemprograman dalam Mind Control Training. Instrumen penelitian yang digunakan dalam penelitian ini Grid Concentration Exercise untuk mengatahui tingkat konsentrasi atlet saat pretest dan posttest. Grid Concentration Exercise dalam penelitian ini diadopsi dari Harris dan Harris (1984).

Pada penelitian ini menggunakan statistik non parametrik dengan teknik analisis data adalah uji wilcoxon dan gain score dengan bantuan Statistical Product and Service Solution (SPSS) versi 20.0 for windows.

\section{Hasil}

Berdasarkan penelitian yang telah dilakukan, diperoleh hasil pretest dan posttest kedua kelompok sebagai berikut:

Tabel 2. Hasil Pretest dan Posttest

\begin{tabular}{|c|l|c|c|c|c|c|c|c|c|}
\hline \multirow{2}{*}{$\mathbf{N}$} & \multicolumn{4}{|c|}{ Eksperimen } & \multirow{4}{*}{ Kontrol } \\
\cline { 2 - 6 } \cline { 7 - 10 } & $\mathbf{S}$ & Pr & Po & $\mathbf{G}$ & & $\mathbf{S}$ & Pr & Po & $\mathbf{G}$ \\
\hline 1 & JLR & 5 & 21 & 16 & 1 & ODS & 4 & 11 & 7 \\
\hline 2 & JIS & 6 & 16 & 10 & 2 & ADA & 8 & 10 & $2^{\mathrm{b}}$ \\
\hline 3 & AJE & 5 & 23 & 18 & 3 & CFA & 4 & 7 & $3^{n}$ \\
\hline 4 & UFJ & 10 & 20 & 10 & 4 & OND & 10 & 11 & $1 \mathrm{~m}$ \\
\hline 5 & LAF & 9 & 15 & 6 & 5 & LSH & 9 & 13 & $4 \mathrm{~d}$ \\
\hline 6 & KHA & 9 & 26 & 17 & 6 & PAG & 9 & 9 & 9 \\
\hline 7 & INA & 11 & 20 & 9 & 7 & PEF & 11 & 7 & -4 \\
\hline
\end{tabular}

Pembahasan

Hasil penelitian yang menunjukkan Training pada kelompok eksperimen nilai signifikansi yang diperoleh sebesar 0,012 lebih kecil dari nilai probabilitas sebesar 0,05 . Berarti dapat disimpulkan bahwa terdapat perbedaan antara sebelum dan sesudah diberikannya pelakuan, sehingga hipotesis peneliti diterima dimana ada pengaruh Mind Control Training terhadap peningkatan konsentrasi pada atlet putri UKM Bola Voli Unesa.

wa Mind Control Training sebagai nental training yang efektif untuk meningkatkan konsentrasi atlet ini selaras dengan pendapat Sholichah dan Jannah 2015) yang menyatakan bahwa metode Iraining merupakan metode yang efektif 
untuk pengembangan sumber daya manusia tak terkecuali untuk atlet. Hal tersebut sesuai dengan pendapat Ivancevich, dkk (2007) yang menyatakan bahwa training merupakan sebuah proses sistematis untuk mengubah seseorang atau sekelompok dalam usaha meningkatkan kinerja. Bentuk mental training yang diberikan dalam penelitian ini adalah Mind Control Training yang mengacu pada Silva Method. Silva Method ini meliputi konsep meditasi, visualisasi, hipnosis, dan positive thinking (Silva, 2007; Dyar, 2012). Bentuk Mind Control dalam metode ini terjadi pada tahap pemprograman ketika subjek mengontrol pikirannya tentang stimulus internal dan eksternal yang mempengaruhi konsentrasi.

Wilson, dkk (2006) menjelaskan bahwa konsentrasi adalah suatu kemampuan untuk memfokuskan perhatian pada satu tugas dan tidak terganggu oleh stimulus internal dan stimulus eksternal. Stimulus internal dan stimulus eksternal merupakan dua kategori terpisah, tetapi secara terus-menerus dapat mempengaruhi perhatian dan konsentrasi atlet (Wilson, dkk, 2006). Stimulus internal merupakan stimulus yang berasal dalam diri atlet (Komarudin, 2013). Stimulus internal yang dialami oleh subjek penelitian adalah adalah motivasi dalam diri atlet. Menurut Puspaningrum (2013) apabila motivasi dalam diri atlet menurun, maka atlet sendiri akan sulit untuk berkonsentrasi selama pertandingan.

Stimulus kedua yang mempengaruhi konsentrasi atlet adalah stimulus eksternal. Stimulus eksternal merupakan stimulus yang berasal dari luar diri atlet yang diperoleh melalui indera (Komarudin, 2013; Puspaningrum, 2013). Pada penelitian ini, ada dua indera pada subjek penelitian yang memperoleh stimulus sehingga konsentrasi menjadi turun. Pertama adalah indera penglihatan seperti poin-poin kritis, melihat kemampuan lawan yang lebih baik, dan tulisan-tulisan dari supporter lawan. Jika fungsi visual kacau, maka stimulus yang masuk ke dalam proses persepsi tidak akan sempurna, sehingga proses pemilahan di dalam otak sebagai pusat pemrosesan informasi untuk merespon konsentrasi juga akan terganggu (Puspaningrum, 2013). Kedua adalah indera pendengaran seperti ejekan dan sorakan dari supporter lawan dan suara pelatih yang menekan. Menurut Puspaningrum (2013) apabila atlet mendengarkan ucapan tersebut biasanya akan timbul reaksi emosionalnya dan tingkat emosi yang tinggi yang akan mengganggu daya konsentrasi serta mengganggu fungsi pendengaran yang pada akhirnya mengacaukan konsentrasi.

Adanya dua stimulus ini, menganggu proses shifting konsentrasi atlet, terutama atlet voli yang menggunakan jenis konsentrasi dari broad external (mengamati pergerakan lawan) dan narrow external (melakukan serangan, pertahanan, dan sebagainya) (Nideffer dan Sagal, 2006; Wilson, dkk, 2006; Komarudin, 2013). Menurut Wilson, dkk (2006) untuk mengatasi stimulus eksternal, dilakukan dengan cara strategi pengalaman sebelumnya (previous experience strategy) untuk mengembangkan konsentrasi dan mengontrol gangguan. Previous experience strategy merupakan salah satu bentuk dimana atlet membayangkan pengalaman lalunya dan disertai bagaimana perasaan dan cara menghadapi gangguan (Wilson, dkk, 2006). Previous experience strategy ini dapat dilakukan dengan Mind Control Training yang mengajarkan subjek penelitian untuk memvisualisasikan pengalamanpengalaman lalu dan sekarang ketika bertanding dan dilakukan kinesthetic feedback tentang bagaimana perasaannya ketika memvisualisasikan pertandingan. Visualisasi dan kinesthetic feedback dalam Mind Control Training ini dimaksudkan untuk mengatasi berbagai stimulus eksternal yang dapat menurunkan konsen- 
trasi atlet (Nideffer dan Sagal, 2006; Wilson, dkk, 2006).

Menurut Nideffer (2000) dan Wilson, dkk (2006) untuk mengatasi stimuli internal diperlukan pikiran yang tenang dalam diri untuk untuk dapat berkonsentrasi kembali. Mind Control Training dalam hal ini bertindak sebagai mental training yang membuat atlet menjadi rileks melalui tahap meditasi. Atlet dengan keadaan rileks, tenang, dan nyaman ini akan memasuki tahap pemprograman untuk mengubah pikiranpikiran negatif yang ada pada diri atlet melalui hipnosis dan positive thinking.

Pada atlet sudah merasa tenang dan nyaman, dilakukan pengontrolan pikiran mengenai pikiran-pikiran negatif yang dapat mempengaruhi konsentrasi atlet. Contohnya, atlet yang bertanding mengalami trauma karena kekalahan. Di pertandingan berikutnya, atlet tersebut bertemu lagi dengan atlet yang pernah mengalahkannya. Pada saat subjek memasuki tahap pemprograman, atlet diubah pola pikirnya melalui visualisasi untuk membayangkan bagaimana ia mampu mengalahkan atlet serta hipnosis dan positive thinking yang digunakan untuk mengubah pikiran, persepsi, atau anggapan negatif menjadi positif seperti menjadikan lawan sebagai motivasi saat bertanding atau menganggap bahwa lawan tidak memiliki kemampuan untuk mengalahkannya. Sistem kerja Mind Control dalam tahap pemprograman inilah, membuat atlet mampu mengubah pola pikir negatifnya menjadi positif sehingga dapat mempengaruhi perilakunya saat bertanding

Hasil penelitian ini yang menyatakan bahwa Mind Control Training efektif untuk meningkatkan konsentrasi atlet putri UKM Bola Voli Unesa juga dipengaruhi oleh beberapa faktor lain yaitu ketertarikan subjek penelitian dan rutinnya subjek penelitian menjalani mental training bersamaan dengan latihan fisik dan teknik.
Hal tersebut terlihat berdasarkan hasil wawancara pada delapan subjek tanggal 23 November 2015, mereka menyatakan belum pernah memperoleh latihan mental Mind Control Training. Subjek penelitian menyatakan bahwa mereka pernah mengikuti mental training seperti hipnosis, meditasi, dan relaksasi. Berdasarkan wawancara tersebut juga, subjek penelitian mengatakan masih asing dengan Mind Control Training, sehingga peneliti memberikan penjelasan (briefing) pada tanggal 23 November 2015 pukul 18.00 WIB hingga 18.45 WIB mengenai apa itu Mind Control Training sebagai salah satu mental training yang memberikan pengaruh besar dalam diri atlet.

Tujuan briefing ini adalah supaya subjek penelitian memperoleh gambaran mengenai perbedaan antara Mind Control Training dan mental training yang pernah diikuti sebelumnya seperti hipnosis, meditasi, relaksasi, dan sebagainya. Berdasarkan hasil briefing inilah, subjek penelitian memperoleh gambaran tentang manfaat Mind Control Training bagi dirinya dan subjek merasa tertarik untuk mempelajari Mind Control Training dengan menyatakan kesediannya untuk mengikuti mental training sesuai dengan prosedur peneliti dengan ditandatanganinya informed consent

Faktor selanjutnya yang mempengaruhi peningkatan konsentrasi dalam penelitian ini adalah setiap kali diberikan perlakuan, subjek penelitian mengimbangi mental training tersebut dengan latihan fisik dan latihan teknik. Hal tersebut dimaksudkan agar subjek penelitian merasakan dampak secara langsung dari Mind Control Training ketika mereka berlatih. Subjek penelitian dalam penelitian ini rutin melaksanakan latihan mental, fisik, dan teknik selama penelitian, sehingga menimbulkan proses otomatisasi dalam diri subjek penelitian ketika menghadapi kejadian yang serupa dimana subjek penelitian akan terbiasa dan mampu 
untuk menangani permasalahn konsentrasi yang ada dalam dirinya.

Temuan dalam penelitian ini sesuai dengan apa yang diungkapkan Silva (2007) bahwa dengan melakukan Mind Control Training, seseorang dapat memelihara konsentrasinya lebih baik. Hasil penelitian ini sejalan dengan hasil penelitian yang dilakukan oleh Fauzee, dkk (2009); Stankovic, dkk (2011); Shahbazzadegan, Samadzadeh, Abbasi (2013); Baltzell dan Akhtar (2014); dan Jalene dan Wulf (2014) yang mana latihan mental sejenis Mind Control Training efektif untuk meningkatkan kemampuan atlet salah satunya adalah konsentrasi.

Berdasarkan penjelasan yang telah diuraikan sebelumnya, dapat disimpulkan bahwa dengan mental training seperti Mind Control Training inilah, atlet dapat mencoba untuk memelihara tingkat konsentrasinya (Silva, 2007; Dyar, 2012). Tingkat konsentrasi yang optimal merupakan salah satu aspek psikologis yang dapat mendukung aspek fisik dan aspek teknik yang dimiliki oleh atlet sehingga atlet mampu untuk mencapai suatu prestasi yang gemilang (Nideffer, 2000; Wilson, Peper, dan Schmid, 2006; Adisasmito, 2007; Gunarsa, 2008; Komarudin, 2013).

\section{Simpulan}

Berdasarkan penelitian yang telah dilakukan, diperoleh kesimpulan bahwa Mind Control Training memberikan efek positif pada peningkatan konsentrasi pada atlet putri UKM Bola Voli Unesa, sehingga Mind Control Training terbukti untuk meningkatkan konsentrasi atlet putri UKM Bola Voli Unesa.

Akurasi hasil penelitian ini dapat ditingkatkan dengan memperbaiki prosedur eksperimen berikut. Bagi peneliti selanjutOnya disarankan agar menggunakan singleblind procedure untuk membatasi pengetahuan subjek mengenai perlakuan yang diberikan atau dengan kata lain, subjek penelitian tidak mengetahui bahwa ia sedang diteliti. Saran lainnya adalah menggunakan desain true-experiment, menambah jumlah sampel, dan mempertimbangkan variasi personal seperti tipe kepribadian subjek penelitian.

\section{Daftar Pustaka}

Adisasmito, L. (2007). Mental juara modal berprestasi. Jakarta: Raja Grafindo Persada.

Amini, F., Esteki, M., dan Entezar, R. K. (2014). Relationship between creativity level and the alpha and theta brain wave in neurofeedback baseline. International Journal of Psychology and Behavioral Research, 3 (4), 287-292.

Baltzell. A., dan Akhtar V. L. (2014). Mindfulness meditation training for sport (MMTS) intervention: Impact of MMTS with division I female athletes. The journal of Happiness \& Well-Being, 2 (2), 160-173.
Bazanova, O. (2012). Comment for current interpretation eeg alpha activity: a review and analysis. Journal of Behavioral dan Brain Science, 2, 239-248.

Cox, R. H. (2002). Sport psychology: concept and application. Boston: McGraw-Hill.

Dyar, L. A. (2012). Pelatihan metode silva. Silva Indonesia. diperoleh Oktober 18, 2015, dari http://www.silvaindonesia.com.

Fauzee, M. S. O., Daud, W. R. B. W., Abduallah, R., dan Rashid, S. A. (2009). The effectiveness of imagery and coping strategies in 
sport performance. Journal of Social Science, 9 (1), 97-108.

Gelinas, R., dan Chandler, K. M. (2006). Research note: psychological skills for successful ice hockey goaltenders. Athletic Insight: The Online Journal of Sport Psychology, 8 (2), 64-71.

Harris, D. V., dan Harris, B. L. (1984). The athlete's guide to sport psychology: mental skills for physical people. New York: Leisure Press.

Hedstrom, R. (2015). Cue statement: staying focused at critical times. Association for applied sport psychology. diperoleh Oktober 18, 2015 , dari http://www.appliedsportpsych.org

Hurless, N., Mekic, A., Pena, S., Humphries, E., Gentry, H., Nichols, D. F. (2013). Music genre preference and tempo alter alpha and beta human non-musicians. Impulse: The Premiere Undergraduate Neuroscience Journal, 1-11.

Husdarta, H. J. (2011). Manajemen pendidikan jasmani. Bandung: Alfabeta.

Ivancevich, J. M., Konopaske, R., dan Matteson, M. T. (2007). Organizational behavior and management ( $7^{\text {th }}$ edition). Gania, G. (Terj.). Jakarta: Erlangga.

Jalene, S., dan Wulf, G. (2014). Brief hypnotic intervention increases throwing accuracy. International Journal of Sport Science \& Coaching, 9 (1), 198-206.

Langenati, R., dan Jannah, M. (2015). Pengaruh self-hypnosis terhadap konsentrasi pada atlet senam artistik. Character: Jurnal Penelitian Psikologi, 03 (02), 1-6.
Moeloek, D. (1984). Kesehatan dan olahraga. Jakarta: FKUI Press.

Navis, A. A. (2013). Hypnoteaching: revolusi gaya mengajar untuk melejitkan prestasi siswa. Yogyakarta: AR-RUZZ Media.

Nideffer, R. M. (2000). The ethics and practice of applied sport psychology. Ithaca, N. Y.: Mouvement Publications.

Nideffer, R. M., dan Sagal, M. (2006). Concentration and attention control training. In William, J. N. (Ed.). Applied sport psychology: Personal growth to peak performance. New York, NY: McGraw-Hill.

Nugroho, A. (2009). Peningkatan status mental atlet diy dengan mental training. Jurnal Status Mental, 1-14.

Puspaningrum, Q. (2013). Pengaruh latihan meditasi otogenik terhadap peningkatan konsentrasi latihan: Suatu eskperimen terhadap atlet karate kata kei shin kan bandung (Skripsi, Universitas Pendidikan Indonesia, Bandung). Diperoleh dari http://repository.upi.edu/157/

Shahbazzadega, B., Samadzadeh, M., dan Abbasi, M. (2013). The relationship between education of emotional intelligence components and positive thinking with mental health and self-efficacy in female running athletes. Procedia-Social and Behavioral Sciences, 83, 667-671.

Sholichah, I. F., dan Jannah, M. (2015). Pengaruh pelatihan quiet eye training terhadap peningkatan konsentrasi pada atlet bulu tangkis. Character: Jurnal Penelitian Psikologi, 03 (02), 1-5.

Silva, J., dan Bernd, E. (2007). Jose silva's everyday esp: use your mental powers to succed in ever 
aspect of your life. USA: The Career Press, Inc.

Stankovic, D., Rakovic, A., Joksimovic, A., Petkovic, E., dan Joksimovic, D. (2011). Mental imagery and visualization in sport climbing training. APES, 39 (1), 35-38.

Tim Musyawarah Guru Mata Pelajaran Pendidikan Jasmani dan Kesehatan Kota Kediri. (2012). Pendidikan jasmani olahraga dan kesehatan: SMA semester 1. Solo: CV. HaKa MJ.

Wilson, V. E., Peper, E., dan Schmid, A. (2006). Training strategies for concentration. In Williams, J. N. (Ed.). Applied Sport Psychology: Personal Growth to Peak Performance (5th edition). Boston: McGraw Hill.

Zep Iin, S., Galli, N., Visek, A. J., Durham, W., dan Staples, J. (2014). Concentration and attention in sport. SportPsych Works, 2 (1), 1-2.

Zhuang, T., Zhao, H., Tang, Z. (2009). A study of brainwave entrainment based on eeg brain dynamics. Computer and Information Science, 2 (2), 80-86. 